\title{
Dietary Magnesium Supplements - Is there any Problem?
}

\author{
Istvan G Telessy* \\ Department of Pharmaceutics, Faculty of Pharmacy, University of Pécs and MedBioFit Lpc, Fácán sor 25, Gödöllö, Hungary
}

Received: May 22, 2018; Accepted: July 04, 2018; Published: July 23, 2018

*Corresponding author: Istvan G Telessy, Department of Pharmaceutics, Faculty of Pharmacy, University of Pécs and MedBioFit Lpc, Fácán sor 25, Gödöllő, Hungary.E-mail: telessyist@vnet.hu

\section{Introduction}

Supplementation of magnesium (Mg) became a fashion since the news in internet has been published: by administration of magnesium stress-induced problems as well as other mental (eg. anxiety and depression) or cardiovascular ailments (atherosclerosis, post-AMI or arrhythmia) can be prevented or ameliorated.

The pivotal role of $\mathrm{Mg}$ in mood and neurology is known for ages: first study on magnesium vs. stress relation was published in 1947 and since then plenty of scientific studies and reviews in the scientific literature, still even today the existing evidences for rised questions are poor [1-3].

Magnesium is essential to life, it's out of question. But really do we need as much supplementation as we do today? Since magnesium-containing products are freely available as OTC drugs or dietary supplements, advertisment of such products got a huge accession. Dysmagnesemia may be a common problem and yet appropriate supplementation of magnesium is not as obvious as the insertions suggests it. We here present a review article addressing the theme.

\section{Magnesium, the Indispensible Cation}

Magnesium is structural element in cell membrane, bone, and the chromosomes. It plays an important role in the cellular functions and nerve transmission. $\mathrm{Mg}$ is co-factor of more than 300 enzymes, part of all anabolic as well as catabolic processes like glycolysis, fatty acid oxidation and other biochemical reactions like blood pressure control and blood glucose regulation as well as amino acid metabolism or protein synthesis [4]. $\mathrm{Mg}$ is stored mainly in the bones $(60 \%)$ and the muscles $(30 \%)$, in the blood one can find just ca. 1\%. The blood levels of Mg are kept constant mainly by the bone exchangeable pool and the proper kidney function.

Magnesium is basically the second mostabundant intracellular cation therefore its extracellular level is not always a reliable indicator of the clinical efficacy. (Max. 1-3\% of total amount located extracellulatly and ca. $0,3 \%$ in the serum.) Even if so, according to animal data, relation of se-level to IC concentration of magnesium (red blood cells) is relatively constant $(0,4: 1)$. The equilibration time between Extracellular (EC) and Intracellular (IC) spaces is slow, takes weeks or month. Normal value of $\mathrm{Mg}$ in the serum is between $0.75-1.15 \mathrm{mmol} / \mathrm{L}(1.8-2.7 \mathrm{mg} / \mathrm{dl})$. Here, $\mathrm{Mg}$ is found in three fractions: ca. $55-70 \%$ is in ionized form, 20 $30 \%$ is in protein-bound and the rest is in complex form with any of the anions (5-15\%).

Magnesium household in essence is regulated by uptake and excretion. Gastrointestinal (GI) absorption of Mg takes place in the small intestine by active carrier-mediated process and by constant transcellular and concentration-dependent paracellular diffusion mainly in the jejunum and ileum. Absorption of magnesium-derivates under standard conditions are reported in Table 1. However absorption practice is concentrationcontrolled: in high intraluminar Mg-content decreased, in low content high absorption was detected. In a smaller extent there is transcellular absorption in the colon, too, which is saturable fashion. Magnesium-salts are administered with various purposes and absorption rate is also differrent Table 2. As we see during high dose Mg-containing antacid and laxative/purgative therapy, the magnesium absorption is limited [5]. Under such situation max. $10 \%$ of administered Mg-ion appears in the circulation. In these indications mainly inorganic Mg-compounds are used, like $\mathrm{MgO}, \mathrm{Mg}(\mathrm{OH})_{2}, \mathrm{MgSiO}_{3}, \mathrm{MgCO}_{3}$ and their combinations as well as $\mathrm{MgSO}_{4}$, respectively. Normal absorption of magnesium in the GI tract requires the presence of selenium, parathyroid hormone and vitamins B6 and D. The high fat load and high phosphate content of the chimus hinder the absorption of $\mathrm{Mg}$, simultaneous

\begin{tabular}{|c|c|}
\hline \multicolumn{2}{|c|}{ Table 1: Human GI absorption of magnesium salts } \\
\hline Mg-salts & Absorption after oral aministration (\%) \\
\hline Mg-aspartate & 44.5 \\
\hline Mg-lactate & 42.3 \\
\hline Mg-citrate & 29.6 \\
\hline Mg-glycinate & 23.5 \\
\hline Mg-oxide & 22.8 \\
\hline Mg-chloride & 19.7 \\
\hline Mg-gluconate & 19.2 \\
\hline Mg-sulfate & 4 \\
\hline
\end{tabular}




\begin{tabular}{|c|c|}
\hline Magnesium salt & Main use \\
\hline $\begin{array}{l}\text { Magnesium-aluminium } \\
\text { silicate }\end{array}$ & pharmaceutical excipient \\
\hline Magnesium asparaginate & cardiovascular protection \\
\hline Magnesium chloride & $\begin{array}{l}\text { Mg replacement, cardiovasc. protection, } \\
\text { bone health }\end{array}$ \\
\hline Magnesium citrate & $\begin{array}{l}\text { urine-pH regulator, cholecystokinin } \\
\text { release enhancer }\end{array}$ \\
\hline Magnesium gluconate & intravenous antidote in toxicology \\
\hline Magnesium hydoxide & antacid \\
\hline Magnesium lactate & acidity regulator \\
\hline Magnesium orotate & cardiovascular protection \\
\hline Magnesium pidolate & $\begin{array}{l}\text { Mg replacement, cardiovasc. protection, } \\
\text { bone health }\end{array}$ \\
\hline Magnesium stearate & $\begin{array}{l}\text { lubricant in the preparation of } \\
\text { compressed tablets }\end{array}$ \\
\hline Magnesium sulfate & $\begin{array}{l}\text { laxative and cathartic; Mg replacement } \\
\text { (iv) }\end{array}$ \\
\hline Magnesium trisilicate & absorbent and antacid \\
\hline
\end{tabular}

high calcium intake also decreases Mg absorption [6, 7]. Some of the medications alter absorption of magnesium, too Table

3. Magnesium is widely distributed in the soft tissues and the

Table 3: Drugs with decreased absorption or efficacy due to presence of magnesium salts

\begin{tabular}{|c|c|}
\hline Reduced absorption & Digoxin \\
\hline & beta-adrenerg rec. blockers \\
\hline & nitrofurantoin \\
\hline & rosuvastatin \\
\hline Decreased Efficacy & biphosphonates \\
\hline & antimalarian agents \\
\hline & vitamin K antagonists \\
\hline & tetracyclines \\
\hline & quinolones \\
\hline & penicillamine \\
\hline
\end{tabular}

bones. Excretion dominantly takes place in the kidneys, in small extent eliminates by faeces, its renal threshold is $14 \mathrm{mg} /$ liter and excess amount is rapidly excreted [8]. The kidneys are the major regulator of magnesium homeostasis. Out of the ca. $2400 \mathrm{mg} \mathrm{Mg}$ excreted daily in the glomeruli ca. $2300 \mathrm{mg}$ immediately resorbed in the Henle's loop and proximal tube. Due to the excellent resorption the $\mathrm{Mg}$ recirculation is nearly complete. Individuals can lose considerable amount of magnesium by sweatening and diarrhoea as well. Some medicines like diuretics (often part of antihypertensive treatment!) enhance Mg-loss, too. Kidneydisease, however, may also worsen excretion and thus induce eg. bradycardia. Absorption and excretion is under hormonal control. However, there is no one single hormon responsible for Mg homeostasis but parathyroid hormone, estrogen, calcitonin, glucagon and 1,25-dihydroxyvitamin D surely influence together the balance of intake, utilization and excretion $[9,10]$.

Magnesium should be discussed as part of the electrolytehousehold where alterations of different ions are influencing others. As competitor for many calcium-binding sites, $\mathrm{Ca}$ and $\mathrm{Mg}$ are counterparts in the cardiovascular as well as in the neuromuscular system. Worthy of note that in order to keep the homeostasis presumably there is an optimal intake of Ca++ and $\mathrm{Mg++}$. Sato and coworkers demonstrated a significant correlation between high Ca:Mg ratio and all-cause and cardiovascular mortality among dialysis patients [11]. Durlach recommended that in order to maintain healthy relations total dietary Ca:Mg ratio should remain close to 2.0 [12]. Magnesium blocks the repolarization of $\mathrm{Ca}++$-channels therefore used as first choice drug in cardiac surgery for treatment of tachycardias, first of all atrial fibrillation [13]. Mg supplementation can modify the intracellular ratio of Ca:Mg which affects - as demonstrated by in vitro studies - physiological processes and cell proliferation [14]. Observations are, however contradictory. The ratio of $\mathrm{Ca}: \mathrm{Mg}$ in generally consumed food is steadily increasing in the last 4-6 decades and propagation of several disease (metabolic and inflammatory syndromes, and some types of cancer) may be in relation with this fact, too [15]. There are different concepts how relative lack of $\mathrm{Mg}$ can contribute to the above mentioned diseases, including the lipoprotein peroxidation, inhibition of Na-K-ATPase, protection against anoxia, alteration in RAAS system, decrease of NO-production, etc. but to date no one clear mechanism is confirmed.

The Framingham Heart Study, on the other hand, demonstrated that magnesium intake was inversly associated with arterial calcification [16]. Some years later an animal study explored the background. The increase in Ca:Mg ratio protected rats against the Ca-deposition in the aorta wall because high Caproportion reduces extracellular pyrophosphate hydrolysis, thus vascular calcification [17]. (Extracellular pyrophosphate is a potent inhibitor of vascular calcification.)

With regard to other noncommunicable diseases Dai, Steck and others observed a positive correlation between higher $\mathrm{Ca}: \mathrm{Mg}$ ratio and higher odds of higher aggressive prostate cancer [18, 19]. The mechanisms behind are not yet known. The picture is more coloured in case of other cancer types: in a study high Ca:Mg ratio resulted in reduced risk of all-cause mortality in women with breast cancer however, there were no statistically significant association between $\mathrm{Mg}$ and Ca intakes and breast cancer-specific mortality [20]. Zhu and co-workers found that high Ca:Mg intake ratio tended to be associated with reduced risk of colorectal adenoma but in those who carried GG genotype, high Ca:Mg ratio was associated with increased odds of colorectal ademona [21, 
22]. This means genetic variations (eg. SLC7A2 and other gene polymorphism) may stand behind this type of carcinogenesis.

\section{The Magnesium Deficiency}

Magnesium deficiency means that total amount of this cation is unsufficient to maintain all healthy processes in the body. Diminished amount of stored magnesium is called Hypomagnesemia (HM) and should be restored, othervise pathological changes will occur. In spite of the temporal differences between IC and EC magnesium levels, hypomagnesemia is usually declared in medicine as serum concentration less than 0.75 $\mathrm{mmol} /$ liter $(1.8 \mathrm{mg} / \mathrm{dl})$.

Hypomagnesemia is not a rare alteration, maybe $15 \%$ in the general population [23]. The U.S. Department of Health and Human Services identified magnesium - among other micronutrients - as underconsumed nutrient [24]. The prevalence of hypomagnesemia was in Germany (2001) 14,5\% [25]. In Spain, a study performed among postmenopausal ladies, found $23 \%$ frequency of HM [26]. Mg-deficit in gerontologic population was found by Arinzon et, al in 36\%, more of them presented the laboratory markers of malnutrition [27]. Malnutrition was mainly attributed to the peritoneal dialysis patients in the study of Ye et, al too. They found prevalece of HM in $40,5 \%$ of patients [28]. It has been suggested that some of the medications increase prevalence of hypomagnesemia. First of all chronic diuretic consumption and continuous PPI-use should be mentioned, however just one single doses of hydrochlorothiazide can also increase renal excretion of magnesium $[29,30]$. Table 4 contains the most concerned main ingredients. It seems development of hypomagnesemia is coupled with coincidence of several factors. There are also genetic disorders that play a role in development of HM either in altered absorption (eg. TRMP7 deficiency) or in various kidney diseases, which also frequently result in hypomagnesemia, too [31, 32].

\begin{tabular}{|c|c|}
\hline \multicolumn{2}{|c|}{ Table 4: Drugs inducing hypomagnesemia } \\
\hline $\begin{array}{c}\text { Drugs or therapeutic } \\
\text { groups }\end{array}$ & Example of drug \\
\hline Diuretics & furosemide, thiazoles \\
\hline Proton pump inhibitors & omeprazole, esomeprazole \\
\hline Antimicrobials & aminoglycosides, amphotericin B \\
\hline Immunsuppressiva & cyclosporine-A, tacrolimus, sirolimus \\
\hline Platinum derivatives & cisplatin, carboplatin \\
\hline Monoclonal antibodies & cetuximab, panitumumab \\
\hline
\end{tabular}

Hypomagnesemia, especially mild one does not cause symptoms. Therefore latent magnesium deficiency is of frequent occurence. The joint occurence of HM and diabetes and/or hypertension is quite frequent. In a cohort of nearly 4.000 apparently healthy 6-10 and 11-15 years old children GuerreroRomero et, al. reported incidence of prehypertension and hypertension in $12-14 \%$ and $6-10 \%$, respectively and among them HM was present in 45,6 and $49,6 \%$, respectively [32].
Medium-level deficit can precipitate transient muscle cramps, arrhythmia. In chronic shortage of $\mathrm{Mg}$ intake hypertension, type-2-diabetes and obesity (high body fat content) in general: metabolic syndrome and chronic kidney disease can be detected [33]. And conversely it is verified that T2DM alone decrease Mg se-level [34, 35]. Nearly half of the migrain-patienes have magnesium deficit [36]. Main symptomes of severely low seMg level are neuromuscular disturbances, muscle spasms and seizures, hypokalemia, cardiovascular diseases, anorexia, nausea, vomiting, abdominal pain, etc.

Dietary magnesium requirement for adults is ca. 320 [female] to $420 \mathrm{mg}$ [male] [37]. Today, average intake from highly processed and artificially produced food hardly covers this amount because the $\mathrm{Mg}$-content of vegetables and fruits lately declined by $10-84 \%[38,39]$. The general, food today contains small amount of Mg-derivates additionally, due to slimming diet, regular alcohol-consumption, old age, short bowel syndrome and various GI disorders magnesium-deficit is a relatively common status Table 5. Moreover, large amounts of fiber-

Table 5: Magnesium content of selected foods per portion

\begin{tabular}{|c|c|}
\hline Food (1 portion) & Mg content (in mg) \\
\hline all-bran (45g) & 90 \\
\hline muesly (95g) & 90 \\
\hline Brazil nuts (30g) & 80 \\
\hline peanuts $(30 \mathrm{~g})$ & 70 \\
\hline boiled pasta, brown (150g) & 60 \\
\hline boiled rice, brown (165g) & 60 \\
\hline baked beans (200g) & 60 \\
\hline hazelnuts (30g) & 50 \\
\hline bran flakes (45g) & 50 \\
\hline boiled lentils (105g) & 50 \\
\hline almonds (20g) & 50 \\
\hline Bread, brown (60g) & 40 \\
\hline Sardines, canned (70g) & 35 \\
\hline banana (1 pc) & 35 \\
\hline milk, skimmed (250 ml) & 30 \\
\hline white fish, cooked (150g) & 30 \\
\hline yoghurt (150g) & 30 \\
\hline meet, cooked (100g) & 25 \\
\hline boiled pasta, white (150g) & 25 \\
\hline lamb liver, cooked (90 g) & 20 \\
\hline orange (1pc) & 20 \\
\hline boiled potatoes (150g) & 20 \\
\hline boiled rice, white (165g) & 15 \\
\hline cheese $(50 \mathrm{~g})$ & 12 \\
\hline egg (1 pc) & 10 \\
\hline
\end{tabular}


containing food and low amounts of ingested protein decrease magnesium utilization. The food poor in magnesium impairs normal growth of lean body mass and normal bone development as demonstrated by Bertinato et, al. in animal experiences [40]. In a recent review subclinical magnesium deficit, caused mainly by inadequate $\mathrm{Mg}$ intake from food, is considered to be principal driver of cardiovascular diseases [41]. A korean cross-sectional study demonstrate that traditional korean food containing high proportion of plant food ie. high amount of Mg can, by implication, protect from high blood pressure [42]. Thus in the course of western-type lifestyle a turn in diet and/or supplementation of $\mathrm{Mg}$ may be often advisable.

\section{Mg Supplementation}

The reasons for administration of magnesium are to compensate magnesium deficit (supplementation) or release pharmacological actions (pharmaconutrients). In the second version positive pharmacodynamic effect is expected at supraphysiological doses. For example dose of intravenous magnesium sulphate in preeclampsia / eclampsia indication is 4-6 grams $[43,44]$.

In general, relative deficit of a macro- or micronutrient can be replaced by targeted feeding (preference or dispreference of selected foods) or by dietary supplements. In general, magnesium supplements are claimed to have beneficial effect in prevention as well as in the treatment of several illnesses.

Due to slow equilibrium homeostasis can only slowly be changed, therefore extended oral administration will bring long lasting Mg-retention in hypomagnesemia. Some 4 month magnesium supplementation of obese women resulted in significant decrease of ALT, meaning amelioration of HM-induced low-grade inflammation representing presence of metabolic syndrome [45]. In an other study effect of Mg-supplementation was assessed in migrain patients. Here the reduction of migrain days was in correlation with the duration of therapy: best results were registered after 3 month treatment even if the statistical significance failed [46]. Supposedly magnesium supplementation is essential in prevention of various cardiovascular disease and metabolic syndrome as well $[33,47]$. Recent studies support that there is a definitive positive correlation between circulating Mglevels and cardiovascular health.

Supplementation and therapy is done with various Mgcontaining compounds. Successful absorption from the GI tract is belived to be dependent on the nature of the magnesium salt that is used. It may be true yet circumstances of absorption $(\mathrm{pH}$, circulation, intraluminar content, state of membranes, etc.) are of similar impact. Animal experiment with stable $\mathrm{Mg}$ isotope verify that ${ }^{26} \mathrm{Mg}$ is sufficiently bioavailable from different Mg salts [48]. Human studies are not fully supporting this observation [49]. Magnesium absorption is, however different from identical amounts Table 2. To date organic Mg-compounds (eg. Mg-lactate, Mg-citrate, Mg fumarate, Mg aspartate, Mg-orotate, Mg-pidolate) are preferred for oral magnesium replacement as their absorption is better than inorganic ones [50]. But the molecular form is not definitive from efficacy point of view. From bioavailability aspects the phase before the absorption (liberation of main ingredient from the solid dosage form eg. tablet or capsule) is of special importance. The formulation (technology of production of solid form) determines how the ingredients will be available for the absorption. Products with similar AUC can differ in eg. timeconcentration profile. By advanced formulation bioavailability can be improved consequently with lower dose side effects and adverse reactions of continuous Mg-supplementation can be avoided or mitigated [51].

\section{The Problem is: Uncertainties in Supplementation}

Here we line up the uncertainities of need for Mg replacement and the safety issues, furthermore the product-dependent and the patient-dependent vagueness.

1. First problem is the verification of hypomagnesemia. The indication of Mg-supplementation is further disturbed by the unsure cut off point of hypomagnesemia. In general the se-level of less than $0,75 \mathrm{mmol} / \mathrm{lit}$ is accepted but in some cases 0,65 is the cut off point but according to other scientists' opinion this threshold should be set in the hight of 0,8 or $0,85 \mathrm{mmol} / \mathrm{L}$ [52, 53]. Assessment of the magnesium level is not obvious part of a routine chemical laboratory evaluation. Most people are taking magnesium supplements based on personal decision. The type of supplement, the dose and the duration is usually not advised by medical doctor. Majority of them take supplement accoding to the actual advertisments, supposing they have hypomagnesemia. The results are ex iuvantibus estimated. Really, a lot of publications mention the inadequate intake of $\mathrm{Mg}$, mainly in the USA population. Still, a 5-years survey from Mayo Clinic, USA, including 65.974 hospitalized patients demonstrates more hypermagnesemia than hypomagnesemia [54]. This means, maybe numbers of consumers take magnesium supplements needlessly.

2. Hypomagnesemia is a type of electrolyte abnormalites. Alterations in se-Mg concentrations are often occult and occur along with alterations in other serum electrolytes. HM often accompanied by hypocalcemia and hypokalemia and other iondisturbancies as mentioned above [55]. This is not known by the general population, and the selective Mg-replacement may cause further deviations in the electrolyte-household. Therefore coordinated supplementation of more or all these ions may be needed.

3. Dose-recommendations of Mg-supplementation waries from daily $250 \mathrm{mg}$ to $720 \mathrm{mg}$. The debate about the "best magnesium compound" to replace missing amount in the human organism is stil open. The action (increase in cell- and tissuemagnesium level) of magnesium supplementation supposedly depends on the type of Mg-salt and the bioavailability, however results are dose-dependent [56-59]. By using the equation serum level $=$ oral dose $\mathrm{x}$ absorption many different products could theoretically reache the same result. But the details of LADME (Liberation, Absorption, Distribution, Metabolism and Excretion) will bring the difference. These conditions usually are 
not known by the consumers, as mentioned above. The pity is that consumers as a rule don't know what quality that specific dosage form represents, what bioavailability profile of the main ingredient has, what individual parameters (inclusive genetic disposition) they have, etc. A lot of authors argue for organic salts but there are data for the opposite result, too [59]. Consumers usually forget about the fact of dose-effect relationship, and the influencing factors or the producers underinform the consumer. Or sometimes the advantages of certain forms of magnesium salts are overrated. Today one can settle that the salt form of magnesium plays as good as marginal role in the bioavailability.

To date there are a myriad of magnesium dietary supplement products all over the world but the main ingredients are not more than 20-25 compounds. Their caracteristics are, however, very different and the final products are also very heterogenous. The point is the release of main ingredient from solid dosage form. More than ten parameters are playing a role in this process starting with the administration conditions (fasted or fed conditions), continued with disintegration of tablets which depends on several factors (excipients, pressing force or coating of the tablet and $\mathrm{pH}$, viscosity and volume of the gastric juice, etc.), too. Therefore the technology how the dosage form is made, ie. the technical quality has a pivotal role in this phase of bioavailability. In the old formulations with one and only manufacturer of the main ingredient and one "best practice" in the production technology there were no major differences in release and bioavailavility [60]. Nowadays one can hardly find two producer who's final products have identical parameters in disintegration, dissolution, absorption due to different morphology and particle size of the main ingredient or the various production processes of choice. Today optimalized dosage forms in comparison to old standard ones can even double the bioavailability of a certain compound $[61,62]$. Or micronization, for example, can also dramatically improve the absorption [63].

4. The absorption and elimination of Mg depend on a lot of factors. For the first time the food itself. Food rich in phytic acid (certain vegetarian diet and beans, nuts, brans, soy products, etc.) can bind Mg in the GI tract thus blocks absorption. Similar inhibitory effect can be observed in case of high doses of other cations, oxalates and various fibres. Contrarily, protein administration, resistant starch, oligosaccharides and mediumchain triglycerides improve absortion of dietary magnesium [64]. But the low serum level of Mg also leads to increased intestinal absorption [65]. As known for ages some ingredients, like vitamin B6 can enhance active transport of $\mathrm{Mg}$ across cell membranes. Similarly, there are other attempts improve adsorption or bioavailability of $\mathrm{Mg}$ by combination with other ingredients [66].

All these unknown factors make supplementation of magnesium obscure and the benefit is incidental.

5. In the course of excretion there are also influencing parameters. The increase of urine $\mathrm{pH}$ and anions (sulphate and ammonium) appears to inhibit renal magnesium reabsorption, consequently magnesium wastage increases [67]. Food can influence urine $\mathrm{pH}$ : protein-reach food increases $\mathrm{H}^{+}$-load (acidic diet) and vegetable-reach food decreases it (alkaline diet). Thus nutrition has an impact in magnesium excretion as well. Siener and Hesse demonstrated that people on vegetarian diet excrete less Mg than others consuming mixed diet [61].

$\mathrm{Mg}$ has a wide range of interactions. First of all magnesium interfere with the absorption of calcium and other bivalent cations of food and other origin. Main emulation between $\mathrm{Mg}^{++}$and $\mathrm{Ca}^{++}$ in the bone-homeostasis is to be mentioned, namely bone density depends mainly on Mg-Ca balance [68]. But neuromuscular function is also a crucial point as Mg antagonise Ca on the the NMDA-receptor* of neurotransmitter glutamate. Intracellular Mglevel is inversely proportional to the open ROMK channel* pores, responsible for kidney-regulation part of potassium homeostasis [69]. All these underline the impact of $\mathrm{Mg}$ in the electrolytehoushold. Magnesium interactions within the pharmacotherapy is also known. Polypharmacy which is more abundant in the aged eldely, influences the intended supplementation and rise concerns. The list of drugs frequently reported to induce hypomagnesemia was presented in Table 4 . The first two groups of drugs are used by millions of patients. But interactions are bilateral, magnesium is able to influence action and efficacy of other drugs, too. Antacids - often contain magnesium-derivates - taken together with drugs or shortly before or after it may reduce absorption of other drugs, eg. beta-blockers, that is taken by millions of patients, by $15-26 \%$ [70]. The bioavailability of rosuvastatine - due to the same interaction, can be dropped to the half of normal [71]. Or calcium-channel blockers (often used as antihypertensive agents) and Mg-containing supplements can increase side-effects (eg. cardiodepression) of Ca-blockers eg. nifedipine [72].

6. The genetic determination of $\mathrm{Mg}$ homeostasis is much stronger than that of sodium or potassium or calcium. Genetic differences may account for differences in vulnerability to $\mathrm{Mg}$ deficit in case of stress-reactions but more authors reviewed several genetic disturbances of magnesium homeostasis in relation to other diseases as well [73-75]. The genetic background of Mg dysregulation is heterogeneous and complex in addition their detection is difficult therefore these alterations on population-level are unpredictable. For instance in case of magnesium-treatment of hypertension we see high variability in effectiveness: good success rate in certain patient groups (high responders) in comparison to others [76, 77].

Sex and race differences (also results of genetic determination) may also contribute in benefitial effect of Mg substitution. In a study of lastyear out of 4.421 individuals men having osteoarthritis profited much more from Mg-administration than women [78]. In the publication of Palacios et, al. magnesium retention was higher (more efficient absorption and less excretion) in blacks than that in whites [79]. There are several other situations, too, where magnesium supplementation doesn't result in expected benefit.

7. Finally let us take the preventive and/or curative value of magnesium-replacement in chronic diseases. As discussed 
above many studies demonstrate the correlation between HM and various chronic diseases and, suggest the benefit of Mg-replacement in controlling one or more components of metabolic syndrome (type- 2 diabetes, hypertension and obesity). In contrast Cappuccio et, al. presented lack of effect of oral magnesium on high blood pressure, 13 years later an analysis of 29 observational studies present negative association between dietary magnesium intake and blood pressure [80, 81]. Further a randomized double-blind study with 3-month $\mathrm{Mg}$ replacement did not bring significant improvement of se-Mg or insulin resistance in patients with metabolic syndrome [82]. Associations between Mg-supplements and cancer diseases were above also discussed in details. The instances pro and contra are numerous. In our opinion to date no clear guidelines are available to decide for whom, what type and dose of supplement under which circumstances and how long should be taken in order to reach definitive preventive or therapeutic results.

*NMDA-receptor $=\mathrm{N}$-methy-d-aspartate receptor, constituent of neuronal Ca-channels (ionotrop receptor family)

*ROMK channel $=$ renal outer medullary $\mathrm{K}$-channel, responsible for efflux of $\mathrm{K}+$ from cells

\section{Conclusion}

Magnesium support by dietary supplements is a very popular intervention for prevention as well as for medical purposes however indication and practices in the circle of consumers are questionable. Main concerns are as follows:

* most individuals take Mg based on advertisements and not according to the real need built upon serum-Mg levels or otherwise verified hypomagnesemia

* magnesium deficit often appears with hypocalcemia, hypokalemia and other electrolyte abnormalities, their correction should be handled simultaneously

* bioavailability of Mg-salts is influenced by several factors, not just by the form of salt therefore Mg-intake is - in contrast to several advertisement - more unpredictable on individial level than expected by the users

* formulation of Mg-supplements (in essence: the quality) plays a pivotal role in the efficacy

* absorption of magnesium salts depends on food and other extrinsic and intrinsic factors therefore the absorbed quantity is very variable

* preventive and therapeutical value of Mg-supplementation is fragile due to wide range of potential interactions

* genetic predisposition may basically determine individual magnesium homeostasis as well as the expected benefit of magnesium supplementation

* debate on correlation between magnesium replacement and disease prevention or therapy of certain aiments is not definitively closed. In some cases there are telling arguments, in others just suspicions
Taken together there are problems with the use of Mgsupplementation. There are misbeliefs and unsubstantiated expectations in the public at large. Use of dietary supplements may be, in general, beneficial but to choose the optimal product and find the correct dosage needs counselling. Sometimes even laboratory determination of serum Mg- and/or ionlevels is necessary. Good marketing can not replace good quality and the competent guidance.

\section{Reference}

1. Lazovik AD, Patton RA. The relative effectiveness of auditory stimulation and motivational stress in precipitating convulsions associated with magnesium deficiency. J Comp Physiol Psychol. 1947;40(3):191-202.

2. Boyle NB, Lawton C, Dye L. The effects of magnesium supplementation on subjective anxiety and stress - a systematic review. Nutrients. 2017;9(5):429-450. doi:10.3390/nu9050429

3. Martinez-González MÁ, Sanchez-Villegas AS. Magnesium intake and depression: the SN cohort. Magnes Res. 2016;29(3):102-111.

4. Gröber U, Schmidt J, Kisters K. Magnesium in prevention and therapy. Nutrients. 2015;7(9):8199-8226. doi: 10.3390/nu7095388

5. Morris ME, Le Roy S, Sutton SC. Absorption of magnesium from orally administered magnesium sulfate in man. J Toxicol Clin Toxicol. 1987;25(5):371-382.

6. Behar J. Effect of calcium on magnesium absorption. Am J Physiol. 1975;229(6):1590-1595.

7. Fulop T. Hypomagnesemia.

8. Rude RK, Ryzen E. TmMg and renal Mg threshold in normal man and in certain pathophysiologic conditions. Magnesium. 1986;5(5-6):273281.

9. Quamme GA, Dirks JH. The physiology of renal magnesium handling. Ren Physiol 1986;9(5):257-269.

10. Stokic E, Romani A, Ilincic B, Kupusinac A, Stosic Z, Isenovic ER. Chronic latent magnesium deficiency in obesity decreases positive effects of vitamin D on cardiometabolic risk indicators. Curr Vasc Pharmacol. 2017. doi: 10.2174/1570161115666170821154841.

11. Sato H, Takeuchi Y, Matsuda K, Saito A, Kagaya S, Fukami H, et al. Evaluation of the predictive value of the serum calcium-magnesium ratio for all-cause and cardiovascular mortality in incident dialysis patients. Cardiorenal Med. 2017;8(1): 50-60. doi: 10.1159/000480739

12. Durlach J. Recommended dietary amounts of magnesium: Mg RDA. Magnes Res. 1989;2(3):195-203.

13. Fairley JL, Zhang L, Glassford NJ, Bellomo R. Magnesium status and magnesium therapy in cardiac surgery: a systematic review and metaanalysis focusing on arrhythmia prevention. J Crit Care. 2017;42:6977. doi: 10.1016/j.jcrc.2017.05.038

14. Farruggia G, Castiglioni S, Sargenti A, Marraccini C, Cazzaniga A, Merolle L, et al. Effects of supplementation with different $\mathrm{Mg}$ salts in cells: is there a clue? Magnes Res. 2014;27(1): 25-34. doi: 10.1684/ mrh.2014.0359

15. Rosanoff A. Rising Ca:Mg intake ratio from food in USA adults: a concern? Magnes Res. 2010;23(4):S181-S193.

16. Hruby A, O’Donnell CJ, Jaques PF, Meigs JB, Hoffmann U, McKeown NM. Magnesium intake is inversely associated with coronary artery calcification: The Framingham Heart Study. LACC Cardiovasc Imaging. 2014;7(1): 59-69. doi: 10.1016/j.jcmg.2013.10.006 
17. Villa-Bellosta R. Impact of magnesium:calcium ratio on calcificatopn of the aorta wall. Plos One. 2017;12(6): e0178872. doi.org/10.1371/ journal.pone. 0178872

18. Dai Q, Motley SS, Smith JA, Concepcion R, Barocas D, Byerly S, et al. Blood magnesium, and the interaction with calcium, on the rick of high-grade prostate cancer. PLoS One. 2011;6(4): e18237. doi: 10.1371/journal.pone.0018237

19. Steck SE, Omofuma OO, Su LJ, Maise AA, Woloszynska-Read A, Johnson $\mathrm{CS}$, et al. Calcium, magnesium, and whole-milk intakes and highaggressive prostate cancer int he North Carolina-Louisiana Prostate Cancer Project (PCaP). Am J Clin Nutr. 2018;107(5):799-807. doi: 10.1093/ajcn/nqy037

20. Tao M-H, Qi Dai, Millen AE, Nie J, Edge SB, Trevisan M, et al. Associations of intakes of magnesium and calcium and survival among women with breast cancer: results from Western New York Exposure and Breast Cancer (WEB) Study. Am J Cancer Res. 2015; 6(1):105-113.

21.Zhu X, Shrubsole MJ, Ness RM, Hibler EA, Cai Q Long J, et al. Calcium/ magnesium intake ratio, but not magnesium intake, interacts with genetic polymorphism in relation to colorectal neoplasia in a twophase study. Mol Carcinog. 2016; 55(10):1449-1457. doi: 10.1002/ mc.22387

22. Sun P, Zhu X, Shrubsole MJ, Ness RM, Hibler EA, Cai Q, et al. Genetic variation in SLCtA2 interacts with calcium and magnesium intakes in modulating the risk of colorectal polyps. J Nutr Biochem. 2017;47:3540. doi: 10.1016/j.jnutbio.2017.04.016

23. Wolf MT. Inherited and acquired disorders of magnesium homeostasis. Curr Opin Pediatr. 2017;29(2):187-198. doi: 10.1097/ MOP.0000000000000450

24.Dietary guidelines. U.S.Department of Health and Human Services; U.S.Department of Agriculture: 2015-2020 Dietary Guidelines for Americans 8th ed. 2015.

25. Schimatschek HF, Rempis R. Prevalence of hypomagnesemia in an unselected German population of 16.000 individuals. Magnes Res. 2001;14(4):283-290.

26. López-González B, Molina-López J, Florea DI, Quintero-Osso B, Pérez de la Cruz A, Planells del Pozo EM. Association between magnesiumdeficient status and anthropometric and clinical-nutritional parameters in postmenopausal women. Nutr Hosp. 2014;29(3): 658664. doi: 10.3305/nh.2014.29.3.7198

27. Arinzon Z, Peisakh A, Schrire S, Berner YN. Prevalence of hypomagnesemia (HM) in a geriatric long-term geriatric (LTG) setting. Arch Gerontol Geriat. 2010;51(1):36-40. doi: 10.1016/j. archger.2009.07.002

28. Ye H, Zhang X, Guo Q Naya Huang, Haiping Mao, Xueqing Yu, et al. Prevalence and factors associated with hypomagnesemis in southern chinese continuous ambulatory peritoneal dialysis patients. Perit Dial Int. 2013;33(4):450-454. doi: 10.3747/pdi.2012.00164

29. Pisani LF, Filippi E, Vavassori S, Munizio N, Vecchi M, Pastorelli L, et al. Effect of proton pump inhibitors on magnesium balance: is there a link to cardiovascular risk. Magnes Res. 2016;29(1):1-10. doi: 10.1684/ mrh.2016.0397

30. Stefiková K, Spustová D, Dzurik R. Acute effect of hydrochlorothiazide on renal calcium and magnesium handling in postmenopausal women. Physiol Res. 1999;48(4):327-330.

31. Blaine J, Chonchol M, Levi M. Renal control of calcium, phosphate and magnesium homeostasis. Clin J Am Soc Nephrol. 2015;10(7): 12571272. doi: 10.2215/CJN.09750913
32.Guerrero-Romero F, Rodriguez-Morán M, Hernández-Ronquillo G, Gómez-Díaz R, Pizano-Zarate ML, Wacher NH, et al. Low serum magnesium levels and its association with high blood pressure in children. J Pediatr. 2016;168:93-98. doi: 10.1016/j.jpeds.2015.09.050

33. Belin RJ. Magnesium physiology and pathogenic mechanisms that contribute to the development of the metabolic syndrome. Magnesium Research. 2007;20(2):107-129.

34. Pham PC, Pham PM, Pham SV, Miller JM, Pham PT, etal. Hypomagnesemis in patients with type 2 diabetes. Clin J Am Soc Nephrol. 2007;2(2):366373.

35. Guerrero-Romero F, Flores-Garcia A, Saldana-Guerrero S, et al. Obesity and hypomagnesemia. Eur J Intern Med. 2016;34:29-33.

36. Mauskop A, Varughese J. Why all migrain patients should be treated with magnesium. J Neural Transm (Vienna). 2012;119(5): 575-579. doi: 10.1007/s00702-012-0790-2

37. NIH 2018.

38. Mayer AM. Historical changes in the mineral content of fruits and vegetables: a cause for concern. Brit Food J. 1997;99(6):207-211.

39. Worthington V. Nutritional quality of organic versus conventional fruits, vegetables and grains. J Alternat Complementer Med. 2001;7(2):161-173.

40. Bertinato J, Lavergne C, Rahimi S, Rachid H, Vu NA, Plouffe LJ, et al. Moderately low magnesium intake impairs growth of lean body mass in obese-prone and obese-resistant rats fed a high-energy diet. Nutrients. 2016;8(5):253. doi: 10.3390/nu8050253

41. DiNicolantonio JJ, O'Keefe JH, Wilson W. Subclinical magnesium deficiency: a principal driver of cardiovascular disease and a public health crisi. Open Heart. 2018;5(1):e000668. doi: 10.1136/ opernhrt-2017-000668

42. Choi MK, Bae YJ. Association of magnesium intake with high blood pressure in korean adults: Korea National Health and Nutrition Examination Survey 2007-2009. PLoS One. 2015. doi:10.1371/ journal.pone.0130405

43. Gordon R, Magee LA, Payne B, Firoz T, Sawchuck D, Tu D, et al. Magnesium sulphate for the management of preeclampsia and eclampsia in low and middle income countries: a systematic review of tested dosing regimens. J Obstet Gynecol Can. 2014;36(2):154-163. doi: 10.1016/S1701-2163(15)30662-9

44. Okusanya BO, Oladapo OT, Long Q P Lumbiganon, G Carroli, Z Qureshi, et al. Clinical pharmacokinetic properties of magnesium sulphate in women with preeclampsia and eclampsia. BJOG. 2016;123(3):356366. doi: 10.1111/1471-0528.13753

45. Rodriguez-Hernandez H, Cervantes-Huerta M, Rodriguez-Moran M, Guerrero-Romero F. Oral magnesium supplementation decreases alanine aminotransferase levels in obese women. Magnes Res. 2010;23(2): 90-96. doi: 10.1684/mrh.2010.0204

46. Gaul C, Diener H-C, Danesch U, et al. Improvement of migraine symptoms with a proprietary supplement containing riboflavin, magnesium and Q10: a randomized, placebo-controlled, doubleblind, multic enter trial. J Headache Pain. 2015;16:516. doi: 10.1186/ s10194-015-0516-6

47. Shechter M. Magnesium and cardiovascular system. Magnes Res. 2010;23(2):60-72. doi: 10.1684/mrh.2010.0202

48. Coudray C, Rambeau M, Feillet-Coudray C, Gueux E, Tressol JC, Mazur A, et al. Study of magnesium bioavailability from ten organic and inorganic Mg salts in Mg-depleted rats using a stable isotope approach. Magnes Res. 2005;18(4):215-223. 
49. Ranade VV, Somberg JC. Biavailability and pharmacokinetics of magnesium after administration of magnesium salts to humans. Am J Ther. 2001;8(5):345-357.

50. Serefko A, Szopa A, Poleszak E. Magnesium and depression. Magnes Res. 2016;29(3):112-119.

51. Dualé C, Cardot JM, Joanny F, Trzeciakiewicz A, Martin E, Pickering G, et al. An advanced formulation of magnesium dietary supplement adapted for a long-term use supplementation improves magnesium bioavailability: in vitro and clinical comparative studies. Biol Trace Elem Res. 2018; doi: 10.1007/s12011-018-1277-2

52.AHA American Heart Association: Guideline for cardiopulmonary resuscitation and emergency cardiovascular care. Part 8: Advanced challenges in resuscitation: Section 1: Life-threatening electrolyte abnormalities. Circulation. 2000. 102:1217-1222.

53. Elin RJ. Assessment of magnesium status for diagnosis and therapy. Magnes Res. 2010;23(4):S194-198. doi: 10.1684/mrh.2010.0213

54.Cheungpasitporn W, Thongprayoon C, Qian Q. Dysmagnesemia in hospitalized patients: prevalence and prognostic importance. Mayo Clin Proc. 2015;90(8):1001-1010. doi: 10.1016/j.mayocp.2015.04.023

55. Hansen B-A, Bruserud O. Hypomagnesemia in critically ill patients. J Intensive Care. 2018;6:21. doi: 10.1186/s40560-018-0291-y

56. Lindberg JS, Zobitz MM, Poindecter JR, Pak CY. Magnesium bioavailability from magnesium citrate and magnesium oxide. A Amer Coll Nutr. 1990;9(1):48-55.

57. Shechter M, Saad T, Shechter A, Koren-Morag N, Silver BB, Matetzky S. Comparison of magnesium status using X-ray dispersion analysis following magnesium oxide and magnesium citrate treatment of healthy subjects. Magnes Res. 2012;25(1): 28-39. doi: 10.1684/ mrh.2012.0305

58. Kisters K. What is the correct magnesium supplement? Magnes Res. 2013;26(1):41-45.

59. Firoz M, Graber M. Bioavailability of US commercial magnesium preparations. Magnes Res. 2001;14(4):257-262.

60. Siener R, Jahnen A, Hesse A. Bioavailability of magnesium from different pharmaceutical formulations. Urol Res. 2011;39(2):123-127.

61. White J, Massey L, Gales SK, Dittus K, Campbell K. Blood and urinary magnesium kinetics after oral magnesium supplements. Clin Ther. 1992;14(5): 678-687.

62. Siener R, Hesse A. Influence of a mixed and a vegetarian diet on urinary excretion and concentration. Brit J Nutr. 1995;73(5): 783-790.

62. Dogterom P, Fu C, Legg T, Chiou YJ, BrandonS. Theabsolutebioavailability and the effect of food on the new magnesium lactate dihidrate extended release caplet in healthy subjects. Drug Dev Ind Pharm. 2018;44(9):1481-1487. doi: 10.1080/03639045.2018.1464020

63. Bujalska-Zadrozny M, Kulik K, Ordak M, Małgorzata Sasinowska-Motyl, Emilia Gąsińska, Anna de Corde, et al. Micronized organic magnesium salts enhance opioid analgesia in rats. PLoS One. 2016;11(10): e0161776.

64. Schuchardt JP, Hahn A. Intestinal absorption and factors influencing bioavailability of magnesium - an update. Curr Nutr Food Sci. 2017;13(4):260-278. doi: 10.2174/1573401313666170427162740

65. Nielsen FH, Johnson LK, Zeng H. Magnesium supplementation improves indicators of low magnesium status and inflammatory stress in adults older than 51 years with poor quality sleep. Magnes Res. 2010;23(4):158-168. doi: 10.1684/mrh.2010.0220
66. Weiss D, Brunk DK, Goodman DA. Scottsdale magnesium study: absorption, cellular uptake, and clinical effectiveness of a time-relase magnesium supplement in a standard adult clinical population. J A Coll Nutr. 2018;37(4):316-327. doi: 10.1080/07315724.2017

67. McDougal WS, Koch MO. Effect of sulfate on calcium and magnesium homeostasis following urinary diversion. Kidney Int. 1989;35(1):105115.

68. Castiglioni S, Cazzaniga A, Albisetti W, Jeanette AM Maier. Magnesium in osteoporosis: current state of knowledge and future research directions. Nutrients. 2013;5(8): 3022-3033. doi: 10.3390/ nu5083022

69. Linas SL, Sharma S.: Hypokalemia and hyperkalemia. Chapter 44 pp. 315-361. in: Parsons, PE, Wiener-Kronish JP (eds.): Critical Care Secrets 5th ed., Elsevier, 2013.

70. Baxter K, Preston CL (eds.): Stockley's Drug Interactions. 10th ed. 2013; Pharmaceutical Press, London.

71. Martin PD, Schneck DW, Dane AL, Warwick MJ. The effect of a combination antacid preparation containing aluminium gydroxide and magnesium hydroxide on rosuvastatin pharmacokinetics. Curr Med Res Opin. 2008;24(4):1231-1235. doi: 10.1185/030079908X280662

72. Davis WB, Wells SR, Kuller JA, Thorp JM Jr. Analysis of risks associated with calcium channel blockade: implications for the obstetriciangynecologist. Obstet Gynecol Surv. 1997;52(3):198-201.

73. Seeling MS. Consequences of magnesium deficiency on the enhancement of stress reactions; prevention and therapeutic implications (a review). A Am Coll Nutr. 1994;13(5):429-446.

74.Schlingmann KP, Konrad M, Seyberth HW. Genetics of hereditary disordrs of magnesium homeostasis. Pediatr Nephrol. 2004; 19(1):1325.

75. Viering DHHM, de Baaij JHF, Walsh SB, Kleta R, Bockenhauer D. Genetic causes of hypomagnesemia, a clinical overview. Pediat Nephrol. 2017;32(7):1123-1135. doi: 10.1007/s00467-016-3416-3

76. Li H, Sun S, Chen J, Xu G, Wang H, Qian Q. et al. Genetics of magnesium disorders. Kidney Dis. 2017;3(3):85-97. doi: 10.1159/000477730

77. Rosanoff A, Plasset MR. Oral magnesium supplements decrease high blood pressure ( $\mathrm{SBP}>155 \mathrm{mmHg}$ ) in hypertensive subjects on antihypertensive medications: a targeted meta-analysis. Magnes Res. 2013;26(3):93-99. doi: 10.1684/mrh.2013.0343

78. Veronese N, Stubbs B, Maggi S, Notarnicola M, Barbagallo M, Firth J, et al. Dietary magnesium and incident fraility in older people at risk for knee osteoarthritis: an eight-year longitudinal study. Nutrients. 2017;9(11):1253-1261. doi: 10.3390/nu9111253

79. Palacios C, Wigertz K, Braun M, Martin BR, McCabe GP, McCabe L, et al. Magnesium retention from metabolic-balance studies in female adolescents: impact of race, dietary salt, and calcium. Am J clin Nutr. 2013;97(5): 1014-1019. doi: 10.3945/ajcn.112.039867

80. Cappuccio FP, Markandu ND, Beynon GW, Shore AC, Sampson B, MacGregor GA et al. Lack of effect of oral magnesium on high blood pressure: a double blind study. Brit Med J. 1985;291(6490): 235-238.

81. Mizushima S, Cappuccio FP, Nichols R, Elliot P. Dietary magnesium intake and blood pressure: a qualitatine overview of the observational studies. J Hum Hypertens. 1998;12(7):447-453.

82. Lima de Souza e Silva ML, Cruz T, Rodrigues LE, Ladeia AM, Bomfim 0 , Olivieri L, et al. Magnesium replacement does not improve insulin resistance in patients with metabolic syndrome: a 12 week randomized double-blind study. J Clin Med Res. 2014;6(6):456-462. doi: $10.14740 /$ jocmr $1580 \mathrm{w}$ 